\title{
ANÁLISE DA MEDIDA PROVISÓRIA 525/2011: AMPLIAÇÃO DA CONTRATAÇÃO TEMPORÁRIA DE PROFESSORES SUBSTITUTOS E "PRECARIZAÇÃO” DO TRABALHO DOCENTE NAS UNIVERSIDADES FEDERAIS
}

\section{ANALYSIS OF PROVISIONAL MEASURE 525/2011: EXPANSION OF THE TEMPORARY EMPLOYMENT OF SUBSTITUTE TEACHERS AND PRECARIZATION OF TEACHING WORK IN UNIVERSITIES FEDERAL}

Pablo Augusto Lima Mourão 1

RESUMO: O trabalho busca elucidar e trazer à discussão os principais problemas com a execução do Programa de Apoio a Planos de Reestruturação e Expansão das Universidades Federais (REUNI), verificando se a Medida Provisória $n^{\circ}$ 525/2011, convertida na Lei $n^{\circ}$ 12.425, de 17 de julho de 2011, que ampliou a contratação temporária de professores substitutos, padece ou não do vício de inconstitucionalidade.

PALAVRAS-CHAVE: Universidades Federais - Contratação temporária.

ABSTRACT: The paper seeks to clarify and bring to discussion the main problems with the execution of Program of Support for the Restructuring and Expansion of Federal Universities, making sure that the Provisional Measure $n^{\circ} .525 / 2011$, converted into Law $n^{\circ}$. 12.425 of July 17, 2011, which extended the temporary hiring of substitute teachers, or not suffer from the vice of unconstitutionality.

KEY-WORDS: Federal Universities - Contracting temporary.

\section{INTRODUÇÃO}

O Programa de Apoio a Planos de Reestruturação e Expansão das Universidades Federais (REUNI), instituído pelo Decreto $n^{\circ} 6.096$, de 24 de abril de 2007, teve como principal objetivo dotar as universidades federais das condições necessárias para ampliação do acesso e permanência na educação superior. É uma das ações que consubstanciam o Plano de Desenvolvimento da Educação - PDE.

O projeto foi visto com bons olhos, pois representava a preocupação do Governo Federal com a democratização do ensino superior público, o que é louvável. Isto é, o projeto tinha como principal objetivo a expansão das universidades federais,

\footnotetext{
${ }^{1}$ Acadêmico de Direito, UFSM. Endereço Eletrônico: pa.augusto.mourao@gmail.com
} 
que seria acompanhada da tão esperada reestruturação universitária, com contratação de novos servidores e ampliação da infraestrutura das universidades.

Tudo parecia perfeito, mas em 14 de fevereiro de 2011, foi editada a Medida Provisória 525 (convertida na Lei $\mathrm{n}^{\mathrm{o}}$ 12.425/2011), que modificou a Lei $\mathrm{n}^{\mathrm{o}}$ 8.745/93, ampliando a contratação temporária de professores substitutos. A referida norma foi aprovada com o objetivo de suprir a enorme demanda gerada pelo REUNI. Com essa alteração, a ampliação da contratação de professores temporários substitutos (chamado de "professor precário", pois não possui os compromissos e vantagens de uma carreira funcional) transforma-se no principal instrumento utilizado para dar impulso a esse projeto de expansão.

Em virtude da importância do tema, o presente trabalho busca verificar se: a) a Medida Provisória fere dispositivo constitucional e se estão presentes os requisitos essenciais para sua edição e b) se tal medida reflete uma opção política contrária ao padrão de qualidade da educação e se agrava ainda mais a precarização do trabalho docente nas Instituições Federais de Ensino, comprometendo a indissociabilidade entre ensino, pesquisa e extensão.

\section{POSSIBILIDADES E LIMITES DA CONTRATAÇÃO TEMPORÁRIA NA ADMINISTRAÇÃO PÚBLICA}

\subsection{Concurso público no Brasil: contexto histórico}

$\mathrm{Na}$ história do Brasil, o concurso público foi consagrado em diversas constituições. A Constituição do Império, de 24 de março de 1824, destacou o amplo acesso aos cargos públicos entre as normas de direitos fundamentais (artigo 179, XIV). Com a Constituição de 24 de fevereiro de 1891, a primeira Carta da República, manteve, em seu artigo 73, o amplo acesso aos cargos públicos.

A Constituição posterior, de 1934, trouxe dispositivo similar, mas alojou em título próprio, retirando-o do rol dos direitos e garantias fundamentais (artigo 168, intitulado "funcionários públicos"), mas foi à primeira vez na história do constitucionalismo brasileiro que houve a menção explicita a "concurso público".

Mais adiante, a Carta de 1937, outorgada por Getúlio Vargas, muito embora tivesse um caráter centralista e autoritário, reintroduziu a questão em comento no rol das normas de direitos fundamentais (artigo 122, § $3^{\circ}$ ). Com as Cartas seguintes (de 1946 e 1967) não houve grandes alterações nesse ponto. 
Foi com a Emenda Constitucional $n^{\circ} 1$, de 17 de outubro de 1969, que se admitiu pela primeira vez a possibilidade de dispensa de concurso público para a primeira investidura em cargo público, cabendo à lei indicar esses casos, nos termos que seguem:

\begin{abstract}
Artigo 97: Os cargos públicos serão acessíveis a todos os brasileiros que preencham os requisitos estabelecidos em lei.

$\S 1^{\circ}$ A primeira investidura em cargo público dependerá de aprovação prévia, em concurso público de provas e títulos, salvo os casos indicados em lei.

$\S 2^{\circ}$ Prescindirá de concurso a nomeação para cargos em comissão, declarados em lei, de livre nomeação e exoneração.
\end{abstract}

A promulgação da Constituição de 1988 é um fato marcante na história do país. Representou a transição de um Estado autoritário e intolerante, que perdurou de 1964 a 1985, para um Estado democrático de direito. Houve, com a nova Carta, uma substancial modificação na organização da administração pública (direta e indireta), que passou a ser orientada, conforme o artigo 37, aos princípios da legalidade, impessoalidade, moralidade, publicidade e eficiência.

Destaca-se a exigência de que a investidura em cargo público depende de aprovação prévia em concurso público, conforme consta no inciso II do artigo 37:

\footnotetext{
Art. 37. A administração pública direta e indireta de qualquer dos Poderes da União, dos Estados, do Distrito Federal e dos Municípios obedecerá aos princípios de legalidade, impessoalidade, moralidade, publicidade e eficiência e, também, ao seguinte:

II - a investidura em cargo ou emprego público depende de aprovação prévia em concurso público de provas ou de provas e títulos, de acordo com a natureza e a complexidade do cargo ou emprego, na forma prevista em lei, ressalvadas as nomeações para cargo em comissão declarado em lei de livre nomeação e exoneração.
}

Conforme análise do dispositivo acima transcrito, para se tornar servidor ou empregado público, é necessário a aprovação em concurso público. É uma regra fundamental que visa a garantir a impessoalidade no trato com a coisa pública.

Essa mudança representa a vontade do constituinte em moralizar o serviço público, passando a haver planejamento e programação para a contratação de pessoal, pelos diversos órgãos e entidades da Administração Pública, em todas as esferas (Federal, Estadual e Distrital). A previsão do concurso público já era prevista em Cartas anteriores, mas foi a partir da Constituição Federal de 1988, que se observou um considerável avanço nesse campo. 
A regulamentação da matéria de forma rígida pela Constituição representou, como percebido, uma importante conquista da sociedade. $\mathrm{O}$ concurso público figura como a forma mais democrática de acesso à Administração Pública, possibilitando, portanto, a igualdade de direitos a todos os cidadãos, a consolidação de um sistema meritório de acesso aos cargos públicos e a necessidade de observância do princípio da moralidade e impessoalidade no trato com a coisa pública. Em outras palavras, essa foi uma das conquistas mais significativas na história institucional do Brasil, característica marcante de um Estado democrático e republicano.

Analisando regra constante da Constituição Portuguesa, Gomes Canotilho e Vital Moreira (2007, p. 661) anotam com precisão:

\begin{abstract}
A regra constitucional do concurso consubstancia um verdadeiro direito a um procedimento justo de recrutamento, vinculado aos princípios constitucionais e legais (igualdade de condições e oportunidades para todos os candidatos, liberdade das candidaturas, divulgação atempada dos métodos e provas de selecção, bem como dos respectivos programas e sistemas de classificação, aplicação de métodos e critérios objectivos de avaliação, neutralidade na composição do júri, direito de recurso). $\mathrm{O}$ concurso assente num procedimento justo é também uma forma de recrutamento baseado no mérito, pois o concurso serve para comprovar competências.
\end{abstract}

Na doutrina nacional, José Afonso da Silva (2007, p. 338), em clássica obra de Direito Constitucional, assevera que o concurso público se afigura como instituto essencial à defesa dos postulados constitucionais que regem a administração pública. Nesse sentido, importante destacar trecho de sua obra:

\footnotetext{
O principio da acessibilidade aos empregos públicos visa essencialmente a realizar o princípio do mérito, que se apura mediante investidura por concurso público de provas ou provas e títulos, de acordo com a natureza e a complexidade do cargo ou emprego, na forma prevista em lei, ressalvadas as nomeações para o cargo em comissão declarado em lei de livre nomeação e exoneração.
}

\title{
2.2. Exceção à regra do concurso público: requisitos para a contratação temporária
}

Conforme o exposto, a regra é a admissão do servidor público mediante concurso. No entanto, o texto constitucional prevê duas exceções a essa regra fundamental: trata-se dos incisos II, in fine e IX do art. 37 da Constituição, nos seguintes termos: 
Art. 37. A administração pública direta e indireta de qualquer dos Poderes da União, dos Estados, do Distrito Federal e dos Municípios obedecerá aos princípios de legalidade, impessoalidade, moralidade, publicidade e eficiência e, também, ao seguinte:

II - a investidura em cargo ou emprego público depende de aprovação prévia em concurso público de provas ou de provas e títulos, de acordo com a natureza e a complexidade do cargo ou emprego, na forma prevista em lei, ressalvadas as nomeações para cargo em comissão declarado em lei de livre nomeação e exoneração;

(...)

IX - a lei estabelecerá os casos de contratação por tempo determinado para atender a necessidade temporária de excepcional interesse público;

O objeto do presente estudo refere-se à segunda exceção, qual seja, a contratação por prazo determinado para atender a "necessidade temporária de excepcional interesse público". Como se trata de exceção, conclui-se que o concurso público se afigura como verdadeiro princípio constitucional. Assim, sua exceção, a contratação temporária sem concurso, deve ser interpretada restritivamente.

A esse respeito, colhe-se importante lição de Maria Zanella Di Pietro (2010, p.), segundo a qual "é preciso que a lei, ao disciplinar esse tipo de contratação, estabeleça regras que assegurem a excepcionalidade da medida, evitando que se transforme em regra geral, a exemplo do que ocorreu na vigência da Constituição anterior, e determine as hipóteses em que a seleção é exigível”. Nesse caso, em reforço ao que foi exposto, Di Pietro cita o julgamento da ADI 3.430/ES, concluindo:

O STF entende que as leis que autorizam contratações temporárias não podem fixar hipóteses abrangentes e genéricas, sem especificar a contingência fática que, presente, indicaria a exigência de um estado de emergência. Desta forma, não basta que a lei simplesmente atribua ao Chefe do Executivo interessado na contratação a competência para estabelecer os casos em que a mesma seria possível.

A jurisprudência do Supremo Tribunal Federal é firme nesse sentido:

EMENTA: CONSTITUCIONAL. LEI ESTADUAL CAPIXABA QUE DISCIPLINOU A CONTRATAÇÃO TEMPORÁRIA DE SERVIDORES PÚBLICOS DA ÁREA DE SAÚDE. POSSÍVEL EXCEÇÃO PREVISTA NO INCISO IX DO ART. 37 DA LEI MAIOR. INCONSTITUCIONALIDADE. ADI JULGADA PROCEDENTE. I - A contratação temporária de servidores sem concurso público é exceção, e não regra na Administração Pública, e há de ser regulamentada por lei do ente federativo que assim disponha. II - Para que se efetue a contratação temporária, é necessário que não apenas seja estipulado o prazo de contratação em lei, mas, principalmente, que o serviço a ser prestado revista-se do caráter da temporariedade. III - O serviço público de saúde é essencial, jamais se pode caracterizar como temporário, razão pela qual não assiste razão à Administração estadual capixaba ao contratar temporariamente servidores para exercer tais funções. IV - Prazo de 
contratação prorrogado por nova lei complementar: inconstitucionalidade. V - É pacífica a jurisprudência desta Corte no sentido de não permitir contratação temporária de servidores para a execução de serviços meramente burocráticos. Ausência de relevância e interesse social nesses casos. VI - Ação que se julga procedente. (ADI 3.430, Rel. Min. Ricardo Lewandowski, julgamento em 12- 8-2009, Plenário, DJe 23-10-2009) ${ }^{2}$.

O E. STF vem decidindo, de forma afinada com a doutrina, que para a contratação temporária é imprescindível: a) que os casos excepcionais estejam previstos em lei; b) que o prazo de contratação seja predeterminado; c) que a necessidade seja temporária e d) que o interesse público seja excepcional.

Nas precisas palavras do Min. Ricardo Lewandowski, relator da ADI 3.430 (primeira ementa acima transcrita), "não basta que a lei, seja ela federal, estadual, distrital ou municipal, autorize a contratação de pessoal por prazo limitado para conformar-se ao texto constitucional, eis que a excepcionalidade das situações emergenciais afasta a possibilidade de que elas, de transitórias, se trasmudem em permanentes".

Nas lições de Juarez Freitas (2004, p. 53-183), a contratação temporária é uma modalidade excepcional, não atendendo ao princípio da moralidade. Dessa forma, deve ser interpretada de forma restritiva:

\begin{abstract}
"exige que, fundamentada e intersubjetivamente, os atos, contratos e procedimentos administrativos venham a ser contemplados e controlados à base da orientação decisiva e substancial que prescreve o dever de a Administração Pública observar, com pronunciado rigor e a maior objetividade possível, os referenciais valorativos da Constituição, cumprindo vivificar, exemplarmente, o combate contra toda e qualquer lesão moral ou imaterial provocada por ações públicas não-universalizáveis, destituídas de probidade e de honradez. (...) Com efeito, o objeto das relações de administração nada mais há de ser do que a realização otimizada dos princípios constitucionais, de sorte a permitir que o vínculo jurídico se aperfeiçoe pelo plexo dos liames volitivos com a vontade, por assim dizer, pública".
\end{abstract}

Para regulamentar o dispositivo constitucional em análise (inciso IX do art. 37), disciplinando as hipóteses em que pode ocorrer a contratação temporária na esfera federal, foi editada a Lei $\mathrm{n}^{\circ}$ 8.745, de 09/12/1993, que estabeleceu os casos de contratações em caráter temporário, bem como as condições de estrita necessidade e transitoriedade no âmbito da administração pública, nos termos que segue:

\footnotetext{
${ }^{2}$ No mesmo sentido: ADI 2.229, Rel. Min. Carlos Velloso, julgamento em 9-6-2004, Plenário, DJ de 256-2004.
} 
Art. $1^{\circ}$ Para atender a necessidade temporária de excepcional interesse público, os órgãos da Administração Federal direta, as autarquias e as fundações públicas poderão efetuar contratação de pessoal por tempo determinado, nas condições e prazos previstos nesta Lei.

A norma, alterada em alguns pontos por legislação posterior ${ }^{3}$, prevê a possibilidade de contratação de professores substitutos pelas instituições federais de ensino, desde que para suprir a falta de docente de carreira em razão de exoneração, demissão, falecimento, aposentadoria, afastamento ou licença.

A contratação se dará por prazo determinado (doze meses), prorrogável por igual período, perfazendo um prazo limite de vinte e quatro meses, conforme artigo $2^{\circ} \mathrm{e}$ incisos da referida Lei (requisitos presentes antes da edição da Medida Provisória 525, de 14 de fevereiro de 2011).

E, em reforço de tudo o até aqui exposto, convém frisar, novamente, que todos os requisitos, acima descritos, devem obrigatoriamente estar presentes no momento da contratação temporária, sob pena de grave violação do texto constitucional.

\section{MEDIDA PROVISÓRIA 525/2011: AMPLIAÇÃO DA CONTRATAÇÃO TEMPORÁRIA DE PROFESSORES SUBSTITUTOS E AFRONTA ÀS EXIGÊNCIAS PREVISTAS NA CONSTITUIÇÃO DE 1988}

\subsection{Medida Provisória 525/2011: principais alterações}

O poder Executivo editou, em 14 de fevereiro de 2011, a Medida Provisória ${ }^{4}$ 525, propondo algumas alterações na Lei $n^{\text {o }}$ 8.745, de 9 dezembro de 1993, que disciplina a contratação de pessoal por tempo determinado para atender necessidade temporária de excepcional interesse público.

As principais alterações da referida MP são:

\footnotetext{
${ }^{3}$ Foi modificada pelas Leis: 9.849 , de 26/10/99, 10.667, de 14/05/03, 11.123, de 07/06/05, 11.204, de 05/12/05, 11.785, de 22/09/08 e, recentemente, pela Medida Provisória 525, de 14 de fevereiro de 2011, convertida na Lei $\mathrm{n}^{\circ} 12.425$, de 17 de junho de 2011.

4 A Medida Provisória é uma espécie normativa que tem origem no Decreto-Lei (extinto pela Constituição de 1988). Foi introduzida no nosso ordenamento jurídico para permitir que o Poder Executivo, através do Presidente da República, tivesse meios para enfrentar situações de crise, que exige uma intervenção urgente. Está prevista no artigo 62 da Constituição Federal, segundo o qual "em caso de relevância e urgência, o Presidente da República poderá adotar medidas provisórias, com força de lei, devendo submetê-las de imediato ao Congresso Nacional". Importante destacar que a Emenda Constitucional $\mathrm{n}^{\circ}$. 32, de 11 de Setembro de 2001, reformou o instituto da Medida Provisória. O objetivo foi aperfeiçoar essa espécie normativa e atenuar o seu caráter autoritário. Entre as novidades introduzidas pela Emenda em referência, menciona-se a vedação da reedição de Medidas Provisórias que tenham perdido sua eficácia por decurso de prazo, fazendo com que a Medida Provisória tenha realmente caráter provisório diferentemente do que ocorria antes da Emenda.
} 
a) criação de uma nova modalidade de contratação temporária de excepcional interesse público, qual seja, a contratação de professores substitutos para a instalação de novas unidades de ensino;

b) ampliação da possibilidade de contratação de professores substitutos, como na hipótese de vacância do cargo, afastamento ou licença, na forma do regulamento e nomeação para ocupar cargo de direção de reitor, vicereitor, pró-reitor e diretor do campus;

c) ampliação do percentual máximo de professores substitutos, aumentando de " $10 \%$ do total de cargos de docentes da carreira" para " $20 \%$, do total de docentes efetivos em exercício na instituição federal de ensino”.

Ademais, acrescentou ao art. $2^{\circ}$ da Lei $n^{\circ} 8.745 / 1993$ o inciso $X$, alterando ainda o seu artigo $4^{\circ}$, nos termos que segue:

Art. $2^{\circ}$ Considera-se necessidade temporária de excepcional interesse público: [...]

$\mathrm{X}$ - admissão de professor para suprir demandas decorrentes da expansão das instituições federais de ensino, respeitados os limites e as condições fixados em ato conjunto dos Ministérios do Planejamento, Orçamento e Gestão e da Educação.

Art. $4^{\circ}$ As contratações serão feitas por tempo determinado, observados os seguintes prazos máximos: (Redação dada pela Lei ${ }^{\circ} 10.667$, de 2003) (Prorrogação de prazo pela Lei n ${ }^{\circ} 11.784$, de 2008) [...]

II - um ano, no caso dos incisos III, IV, das alíneas "d" e "f" do inciso VI e do inciso $\mathrm{X}$ do caput do art. $2^{\circ}$; (Redação dada pela Medida Provisória $\mathrm{n}^{\circ}$ 525, de 2011)

Parágrafo único. É admitida a prorrogação dos contratos: (Incluído pela Lei $\mathrm{n}^{\mathrm{o}}$ 10.667, de 2003) (Vide Lei $\mathrm{n}^{\circ} 11.204$, de 2005)

I - nos casos dos incisos III, IV, VI, alíneas "b", "d" e "f", e X do caput do art. $2^{\circ}$, desde que o prazo total não exceda a dois anos; (Redação dada pela Medida Provisória $n^{\circ} 525$, de 2011).

Na exposição de motivos da MP, assinada pela Ministra do Planejamento, Orçamento e Gestão e pelo Ministro da Educação, a contratação temporária foi destacada como instrumento necessário a dar impulso a esse projeto de expansão, aduzindo que:

Esta medida, em particular, insere-se no contexto de implementação do Programa de Apoio a Planos de Reestruturação e Expansão das Universidades Federais - REUNI, que tem como principal objetivo ampliar o acesso e a permanência de estudantes na educação superior pública. Com esse Programa, o Governo Federal adotou uma série de medidas para retomar o crescimento do ensino superior público, criando condições para que as universidades federais promovam a expansão física, acadêmica e pedagógica da rede federal de educação superior.

Ademais, foi destacado que a demanda total de docentes gerada pelo REUNI era de 15.755 Professores de $3^{\circ}$ Grau. Asseveram que esse quadro está sendo formado 
dentro do cronograma estabelecido, mas a demora na realização dos concursos ameaça o atendimento dos novos cursos criados.

Em outras palavras, alega-se que "a ausência de docentes pode prejudicar os estudantes, as instituições e o interesse público, que demanda profissionais em diversas áreas de atuação". Assim, a ampliação da contratação temporária se justificaria, encaixando-se perfeitamente na expressão "necessidade temporária de excepcional interesse público".

A norma em comento coloca a demanda decorrente da expansão das instituições federais de ensino, instituídas a partir de 2007, como "excepcional interesse público". Assim, o Governo Federal poderá preencher as vagas em novas Universidades e Institutos Federais sem a necessidade imediata de promover concursos públicos para a contratação de professores efetivos.

Fica evidente, dessa forma, que o Executivo pretende expandir o ensino superior público de forma desordenada, sem a devida preocupação com a qualidade do ensino oferecido.

\subsection{Análise dos aspectos jurídicos da MP 525/2011}

Conforme destacado no tópico anterior, a Lei $\mathrm{n}^{\mathrm{o}}$ 8.745, de 09 de dezembro de 1993, foi criada para regulamentar o inciso IX, do art. 37 da Constituição Federal, estabelecendo os casos excepcionais que justificam a contratação temporária, tais como: assistência à situação de calamidade pública, combate a surtos endêmicos, realização de recenseamentos, entre outros, sempre buscando atender a situações emergenciais e temporárias. São casos que demandam contratação urgente, não podendo esperar as etapas de seleção através de concurso público.

Assim, as contratações temporárias devem estar sempre afinadas com o princípio da supremacia do interesse público, satisfazendo, portanto, interesse público primário, cujo objetivo é assegurar o bem estar social. Em hipótese alguma a negligência da Administração pública pode ser causa para afastar a exigência de concurso público.

A "necessidade temporária de excepcional interesse público" não pode servir de álibi para justificar a contratação temporária de forma ampla e irrestrita de servidores, sob pena de fraude ao comando constitucional. Desde a promulgação da referida Lei, em 1993, a contratação temporária vem sendo aplicada de forma equivocada, isto é, o 
instituto vem sendo constantemente deturpado, sob o argumento de falta de dinheiro, falta de autorização e carência temporária de pessoal.

O sentido da expressão "necessidade temporária de excepcional interesse público" vem sendo empregada de forma muito ampla, o que pode dar ensejo a uma fraude sistemática ao concurso público. No caso do REUNI, a contratação temporária serve de válvula de escape para suprir a carência de pessoal ${ }^{5}$.

Tal processo de expansão, ocorrido nos últimos anos, gerou, como consequência, uma enorme demanda de servidores. Em 2008, houve a instituição do Programa e Expansão das Universidades Federais - REUNI ${ }^{6}$, com vista a ampliar o acesso ao ensino superior e reduzir as desigualdades regionais. Com o REUNI foram implantadas, até 2010, 14 novas Universidade Federais e 126 novos campus universitários, distribuídos nas cinco regiões brasileiras.

De acordo com as informações disponibilizadas pelo Ministério da Educação, o número de vagas passou de 109,2 mil em 2003, para 222,4 mil em 2010. Toda essa expansão gerou uma enorme demanda por servidores, em especial professores, mas novos concursos não sugiram de forma suficiente. Os obstáculos governamentais impedem uma expansão sólida, com qualidade, pautada na sincronia entre as necessidades geradas pelo REUNI e a contratação, mediante concurso público, do insumo mais básico/elementar do processo educativo, qual seja, a contratação de professores efetivos.

No caso em questão, verifica-se a admissão de contratação temporária para o exercício de atividades públicas permanentes, que devem ser desempenhadas por servidores públicos devidamente concursados, sob pena, no caso das Universidades, da instituição deixar de cumprir sua finalidade.

Em outras palavras, essa ampliação de professores substitutos interfere diretamente nas atividades de ensino, de pesquisa e de extensão da universidade, uma vez que esse docente é temporário e não pode se engajar em todas as atividades da

\footnotetext{
${ }^{5}$ Cabe aqui, fazer um parêntese para contextualizar a norma em questão. A MP foi editada num momento delicado, de anúncio, no início do novo mandato do Governo Federal, da redução de R\$ 50 bilhões em gastos no Orçamento 2011. Como consequência lógica, diversas áreas foram atingidas com esse corte, como, por exemplo, a suspensão de vários concursos públicos e da nomeação dos aprovados em concursos públicos na esfera federal. Foi nesse momento de corte orçamentário que a Medida Provisória foi editada. Sem a intenção de criar cargos e abrir concursos imediatamente, foi uma forma de suprir a enorme demanda de professores decorrente da expansão das instituições federais de ensino. Recorreu-se, então, à contratação precária de professores.

${ }^{6}$ O Programa REUNI deu continuidade ao processo de expansão das universidades federais iniciado com o Programa Expansão, em 2003.
} 
docência universitária. São os professores efetivos que impulsionam a pesquisa e a extensão na universidade.

Essa indissociabilidade (artigo 207, da Constituição), conforme lembra a Professora Lígia Marcia Martins (2009, p. 5), docente do Departamento de Psicologia da UNESP, é imprescindível para a formação técnica, interdisciplinar e crítica dos alunos. Acrescenta que:

(...) organicamente unidas ao ensino é que a pesquisa e extensão terão, certamente, a máxima expressão na formação superior. Se por um lado, o ensino coloca o aluno em relação com o produto da ciência, a pesquisa o coloca em relação com o seu desenvolvimento, instrumentalizando-o para produzir conhecimentos a partir de sua futura atuação profissional ou em situações planejadas especificamente para este fim. Reafirmando a interdependência entre ensino e pesquisa, Saviani (1984) alerta-nos em relação as suas especificidades, que não podem ser preteridas à custa de se enfraquecer tanto um processo quanto outro.

De fato, a referida norma cria contratação temporária para desenvolvimento de atividades finalísticas, permanentes e habituais da Universidade. Nesse sentido, importante destacar a Ação Direta de Inconstitucionalidade $n^{0} 2.380$, de dezembro de 2000. Na referida ação, o Partido dos Trabalhadores questionou a contratação temporária dos servidores para o Instituto Nacional de Propriedade Industrial (INPI), para a atividade de registro de marcas e patentes.

O Relator da referida ação, Ministro Moreira Alves, deferiu a liminar por entender que o dispositivo questionado era inconstitucional, nos termos que seguem:

(...) esse dispositivo constitucional não permite que a lei que estabelecer os casos de contratação temporária admita que figurem entre eles atividades públicas permanentes que são desempenhadas por servidores públicos devidamente concursados (artigo 37, II, da Carta Magna). Nesse sentido, CELSO BASTOS (...) salienta que com inteiro acerto ADILSON DALLARI o que a lei, a que alude o artigo 37, IX, da Constituição, não poderá fazer, verbis: "está absolutamente claro que não mais se pode admitir pessoal por tempo indeterminado, para exercer funções permanentes, pois o trabalho a ser executado precisa ser, também eventual ou temporário, além do que a contratação somente se justifica para atender um interesse público qualificado como excepcional, ou seja, uma situação extremamente importante que não possa ser atendida de outra forma".

As atividades ordinárias e permanentes dos órgãos públicos devem ser desempenhadas por servidores devidamente concursados. Essa foi à opção do constituinte, promovendo o princípio da isonomia, bem como a meritocracia. Cabe lembrar, que o concurso público é uma importante conquista da sociedade brasileira, 
que apesar da referida norma está prevista em constituições pretéritas, somente com a Constituição de 88 que houve o respeito sistemático desse dispositivo.

Nesse sentido, é importante destacar a preocupação exarada pelo Ex-Ministro Sepúlveda Pertence, em voto proferido na ADI 3.068/DF:

\begin{abstract}
O concurso público foi consagrado por diversas constituições. Passaram-se décadas antes que o Ministério Público Federal conseguisse lograr seu primeiro concurso. Passaram-se mais algumas décadas antes que o primeiro concurso se realizasse para o Ministério Público do Trabalho, e sempre cuidando-se de atividade essenciais com base nas mais belas exposições de motivos. Criaram-se os interinos; criaram-se os DAS e DAI, criaram-se os FAS; todas formas de fraudar a exigência do concurso público, para não falar da ascensão funcional pela qual, no dizer pitoresco do Ministro Octávio Gallotti, lembrando Nelson Rodrigues: “o barbeiro de necrotério virava médico-legista"(grifou-se).
\end{abstract}

Ligado a tal situação está o fato de que a contratação temporária não poderia servir para a instalação de serviços novos. É o que preleciona o Min. Carlos Veloso, no voto proferido no julgamento da ADI 1.219/PB:

Celso Antonio Bandeira de Melo versou o tema. Examinando a cláusula "excepcional interesse público" e os demais requisitos da contratação, escreveu que, desde logo, não se coadunaria com sua índole, contratar pessoal senão para evitar o declínio do serviço ou para restaurar-lhe o padrão indispensável mínimo seriamente deteriorado pela falta de servidores. (...) Em segundo lugar, cumpre que tal contratação seja indispensável; vele dizer, induvidosamente não haja meios de supri-la com remanejamento de pessoal ou redobrado esforço dos servidores já existentes. Em terceiro lugar, sempre na mesma linha de raciocínio, não pode ser efetuada para a instalação ou realização de serviços novos, salvo, é óbvio, quando a irrupção de situações emergentes os exigiria e já agora por motivos indeclináveis, como os de evitar a periclitação da ordem, segurança ou saúde. Em quarto lugar, descaberia contratar por esta via para cargo, função ou emprego de confiança, que isto seria a porta aberta para os desmandos de toda espécie. (Regime Constitucional dos Servidores da Administração Direta e Indireta. Ed. R.T., $2^{a}$ ed., 1991. pp. 82-83). (grifouse).

Também se pode afirmar que não existe a "necessidade temporária", outro requisito constitucional exigido para a contratação temporária (art. 37, IX da CF/88). De fato, o aumento do número de vagas nas instituições de ensino faz com que a necessária ampliação do número de professores configure-se como uma necessidade permanente. A ampliação da rede de ensino e do número de alunos não é temporária, de forma que a necessidade de novos professores também não é.

É possível, aí, vislumbrar que a nova hipótese de contratação infringe a Constituição Federal. Nesse sentido, o fato de a MP 525/2011 limitar expressamente o 
prazo de tais contratações (um ano, prorrogável por mais um) não elidiria a afronta constitucional, como entendeu o Ministro do Supremo Tribunal Federal Ricardo Lewandowski, citando Lucas Rocha Furtado (2007, p. 893), no julgamento da já citada ADI 3.430/ES. Isso porque não basta que o contrato seja fixado por prazo temporário, é necessário que a necessidade dessa contratação também seja temporária:

\begin{abstract}
Com efeito, segundo Lucas Rocha Furtado, a "contratação dos servidores temporários constitui - ou deveria constituir - hipótese de utilização bastante restrita no serviço público". Em outras palavras: “... a legitimidade para contratação temporária prevista na Constituição pressupõe que a necessidade de contratação seja temporária, e não apenas que o contrato firmado com o servidor tenha prazo limitado. Exemplo de evidente equívoco ocorre com a contratação de professores substitutos em universidades federais. Não obstante a contratação desses professores seja feita no prazo determinado, a necessidade da administração é permanente, o que não autoriza a utilização do regime previsto no mencionado art. 37, IX”. (grifou-se).
\end{abstract}

Relegar para segundo plano essa questão da qualidade do ensino oferecido traz sérios problemas, como muito bem observa Francis Campos Borda (2011, p. 4):

Primeiro, pela criação de uma nova categoria de professores no ensino público federal, a saber, o "professor precário", aquele que, sem os compromissos e vantagens de uma carreira funcional, ficará encarregado de instalar uma nova unidade de ensino federal. O segundo aspecto é o aumento do número de professores substitutos. Antes da MP as universidades dispunham de um limite de $10 \%$ do total de cargos docentes, ou seja, computavam-se neste limite os professores cedidos, os casos de licença-saúde, mas, sobretudo, não integravam neste cálculo os próprios professores substitutos, já que estes não ocupam cargo. Note-se que a MP retirou a expressão "cargo", ou seja, poderá ocorrer a contratação de substitutos até o limite de $20 \%$ do total de professores em exercício (e nisto se incluem todos os professores, de modo geral, visitantes, cedidos, estrangeiros, etc.). Sem qualquer demérito ao trabalho dos professores substitutos, é do conhecimento geral de que sua atuação não se equipara àquela dos colegas efetivos que desempenham a docência a partir da tríade ensino- pesquisa-extensão de que trata o artigo 207 da Constituição.

Conforme Moção de Repúdio proposta pela diretoria da ANDES-SN $^{7}$ e aprovada no último dia de atividades, "o governo federal repete prática adotada anteriormente em duas situações bem identificadas na história da educação brasileira, uma na década de 70, em plena ditadura, que resultou na proliferação dos contratos de professores colaboradores, e outra na década de 90, no governo FHC, que conduziu ao

\footnotetext{
${ }^{7}$ Moção de repúdio à edição da MP 525/2011. 30 CONGRESSO do ANDES-SN, realizado no período de 14 a 20 de fevereiro de 2011. Acesso em: 14 de dezembro de 2011.
} 
ciclo de ocupação das vagas docentes por substitutos, admitidos temporariamente, em caráter precário".

Ademais, destaca-se que, no presente caso, a emergência na contratação temporária (defendida pelo Executivo) é fruto de um erro de planejamento na execução dessa política pública, ou uma opção política em criar rapidamente Universidades e novos cursos sem qualquer preocupação com o resultado dessa ação, não havendo, no caso dos novos cursos, um excepcional interesse que justifique a contratação temporária. A criação dos novos cursos deveria ser acompanhada de concursos seletivos para professores efetivos.

Acrescenta-se que, mesmo se estivessem presentes todos os requisitos para a contratação temporária (excepcional interesse público, temporariedade da contratação e hipótese prevista em lei), a situação de urgência tem que ser algo imprevisível. Isso, a toda evidência, não ocorre no caso em análise, uma vez que foi a própria Administração que deu azo ao surgimento dessa hipótese de urgência. Nesse sentido, colhe-se importante lição de Celso Ribeiro Bastos (1992, p. 99), que assim leciona:

\begin{abstract}
Seria importante que a futura lei também deixasse certo que esta situação de excepcionalidade resulta de circunstâncias imprevisíveis pela Administração. Em outras palavras, é necessário que não tenha ela mesma, pela sua inércia, dado azo ao surgimento, por exemplo, de uma hipótese de urgência. Suponha-se: numa carreira pública, na grande maioria dos casos, é plenamente possível realizarem-se os concursos oportunamente, sem necessidade de suprir-se o provimento normal do cargo por um excepcional feito emergencialmente. Aqui, a urgência não resulta de algum evento exterior ao atuar administrativo cuja ocorrência fosse imprevisível. Pelo contrário. A urgência só se verifica em decorrência da omissão administrativa que, ao não alimentar a carreira com agentes em número suficiente, acaba por gerar, num dado momento, uma situação de premente necessidade de admissão de pessoal. Mas aqui a culpa é, obviamente, da Administração. Hipótese tais que não deverão, em nosso entender, ser contempladas como ensejadoras da contração com fundamento nesse inciso". (grifou-se).
\end{abstract}

Observa-se que há uma significativa diferença em relação à hipótese de contratação de professor substituta prevista no art. $2^{\circ}, \S 1^{\circ}$ da Lei 8.745/1993: naquele caso, a necessidade é temporária porque há um cargo efetivo, porém o servidor que o ocupa está provisoriamente afastado ou o cargo está provisoriamente vago (casos de falecimento ou aposentadoria), aguardando provimento através de concurso público.

Trata-se, reitera-se, de necessidade efetivamente transitória, ao contrário do que ocorre na hipótese versada na MP 525/2011, em que se busca preencher uma 
necessidade permanente que deveria ser satisfeita através da criação de cargos e promoção de concursos.

Assim, a instalação de novos campi das Universidades Federais ou dos Institutos Federais, bem como a criação de novos cursos, geraram uma demanda previsível de servidores e não poderiam ensejar a contratação temporária, mas sim o preenchimento das necessidades através da criação de cargos públicos e realização de concursos para os mesmos.

Além disso, não se pode olvidar que a contratação temporária para a execução de atividades inerentes a cargos efetivos (os quais deveriam ser criados e providos por concurso público), considerando que os contratados são regidos pela CLT, provoca afronta ao dispositivo constitucional que assegura que haverá regime jurídico único para os servidores públicos da administração pública direta, das autarquias e fundações públicas (CF, art. 39).

Conforme restou demonstrado, os requisitos de admissibilidade da referida Medida Provisória não estão presentes, razão pela qual carece de constitucionalidade. Importante ressaltar que esse controle deveria ser feito pelo Congresso Nacional, mas, infelizmente, esse instituto vem sendo utilizado de forma mais política do que jurídica. Nesse sentido, precisas as palavras de Clèmerson Merlin Clève (1999, p. 118):

[...] lamentavelmente, porém, o Congresso Nacional tem relegado a segundo plano o exercício do controle jurídico das providências normativas de urgência. Consequência: medidas provisórias flagrantemente inconstitucionais têm sido, às dezenas, convertidas em lei. Na prática, o controle duplo vem sendo simplificado até sua redução àquela de natureza exclusivamente política (no menor sentido da expressão, infelizmente)".

Como vimos, a atuação exclusivamente política do Congresso Nacional faz com que Medidas Provisórias flagrantemente inconstitucionais sejam convertidas em Lei, tal como no caso em análise. Essa conversão em Lei não convalida eventuais inconstitucionalidades existentes ${ }^{8}$.

\section{CONSIDERAÇÕES FINAIS}

O Programa de Apoio a Planos de Reestruturação e Expansão das Universidades Federais (REUNI), instituído pelo Decreto $\mathrm{n}^{\circ}$ 6.096, de 24 de abril de 2007, foi um projeto ambicioso, cujo principal objetivo era a ampliação do acesso e permanência no ensino superior. Para a execução desse projeto estava previsto um forte

\footnotetext{
${ }^{8}$ Conforme entendimento do STF nas ADIs 3.090-MC, 3.100-MC e 4.048-MC (entre outras).
} 
movimento de recuperação do orçamento das universidades federais, mas isso não aconteceu.

De fato, houve a expansão das universidades federais, mas não aconteceu a esperada reestruturação universitária, com contratação de novos servidores e ampliação da infraestrutura das universidades. Em outras palavras, os concursos públicos previstos para a contratação de professores efetivos não aconteceu.

Devido à falta de novos investimentos, as universidades não estão conseguindo atingir as metas proposta pelo REUNI. Para suprir a enorme demanda de professores, a solução encontrada foi à edição da Medida Provisória 525, de 14 de fevereiro de 2011 (convertida na Lei $\mathrm{n}^{\mathrm{o}}$ 12.425/2011), que modificou a Lei 8745/93, ampliando a contratação temporária de professores substitutos.

A referida norma ampliou as hipóteses de contratação temporária, para abranger os professores necessários para suprir as demandas decorrentes da expansão das instituições federais de ensino. Pode-se vislumbrar afronta à Constituição Federal à medida que não se trata de situações que versam necessidade temporária. A necessidade de contratação de professores derivada da expansão da rede federal de ensino é permanente.

Ademais, verifica-se outro ponto que merece destaque, qual seja a admissão de contratação temporária para o exercício de atividades públicas ordinárias e permanentes. As atividades permanentes dos órgãos públicos devem ser desempenhadas por servidores públicos devidamente concursados, sob pena, no caso das universidades, da instituição deixar de cumprir sua finalidade.

Em outras palavras, essa ampliação de professores substitutos interfere diretamente nas atividades de ensino, de pesquisa e de extensão da universidade, uma vez que esse docente é temporário e não pode se engajar em todas as atividades da docência universitária. São os professores efetivos que impulsionam a pesquisa e a extensão na universidade.

Sob outra ótica, a contratação temporária não poderia ser realizada para a instalação de novos serviços, os quais demandam a criação de cargos efetivos e realização dos respectivos concursos públicos. Nesse sentido, pode-se vislumbrar ainda afronta à garantia de regime jurídico único para os servidores púbicos, considerando que os contratados estão abrangidos pelo regime celetista.

Portanto, seria possível questionar a constitucionalidade material da medida provisória em questão. Há fundados elementos para a discussão da questão no âmbito 
judicial, especialmente no sentido de que a contratação temporária, em especial nas universidades, desponta, cada vez mais, como instrumento para a contratação discricionária, em caráter precário, transformando a regra, que é o concurso público, em exceção.

\section{REFERÊNCIAS}

AFONSO DA SILVA, José. Curso de Direito Constitucional Positivo. $32^{\mathrm{a}}$ ed. São Paulo: Editora Malheiros, 2009.

BASTOS, Celso Ribeiro. Comentário à Constituição do Brasil. Vol. 3, tomo III. São Paulo: Saraiva, 1992.

BORDA, Francis Campos. Notas preliminares sobre a contratação emergencial para instalação de novas universidades (Medida Provisória 525/2011). Disponível em:http://www.bordas.adv.br/publicacoes_abertos_bordas.asp?subsecao=24\&item $=414$ . Acesso em: 14 de novembro de 2011.

CANOTIlHO, J. J. Gomes; MOREIRA, Vital. Constituição da República Portuguesa anotada. v. 1. São Paulo: Revista dos Tribunais, 2007.

CLÈVE, Clèmerson Merlin. Medidas Provisórias. $2^{a}$ Ed., Curitiba-PR: Max Limonad, 1999.

COSTA, Denise Souza. Dissertação de Mestrado apresentada ao Programa de PósGraduação em Direito da PUC-RS, intitulada "O Direito Fundamental à Educação no Estado Constitucional Contemporâneo e o Desafio da Universalização da Educação Básica”. Disponível em: http://www.dominiopublico.gov.br/pesquisa/DetalheObraForm.do?select_action=\&co obra=191273. Acesso em: 14 de dezembro de 2011.

Diretrizes Gerais do REUNI. Documento Elaborado pelo Grupo Assessor nomeado pela Portaria $n^{\circ} 552$ SESu/MEC, de 25 de junho de 2007, em complemento ao art. $1^{\circ}$ $\S 2^{\circ}$ do Decreto Presidencial $n^{\circ} 6.096$, de 24 de abril de 2007. Acesso em 10 de novembro de 2011.

FREITAS. Juarez de. O Controle dos Atos Administrativos e os Princípios Fundamentais. $4^{a}$ Edição. São Paulo: Malheiros Editores, 2004.

FURTADO, Lucas Rocha. Curso de Direito Administrativo. Belo Horizonte: Fórum, 2007.

MARTINS, Lígia Márcia. Ensino-pesquisa-extensão como fundamento metodológico da construção do conhecimento na Universidade. Disponível em: http://www.franca.unesp.br/oep/Eixo\%202\%20-\%20Tema\%203.pdf. p. 5. Acesso em: 14 de dezembro de 2011. 
SILVA, José Afonso da. Comentário Contextual à Constituição. $3^{\text {a }}$ ed. São Paulo: Malheiros, 2007. 